\title{
SOCIAL CAPITAL AND THE TRANSITION FROM SCHOOL TO WORK
}

\author{
Libby Plumridge
}

\author{
University of Canterbury and CRESA
}

\begin{abstract}
An analysis of the talk of two young men at the end of their year 13 schooling reveals that despite similarities in background, the families and school experiences of each has enabled them to mobilise radically different forms of social capital through social networks. This provides them with radically different resources to envisage and realise their aspirations during the transition from school to work.
\end{abstract}

\section{Introduction}

\section{The Transition 'Problem'}

The issue of youth 'transition' from secondary schooling to the world of work is firmly on the public agenda in New Zealand. The 'problem' in this transition is 'nonparticipation' (Sustainable Development 2003) or what is sometimes termed NEET youth: young people not in employment, education or training towards work (Bynner \& Parsons). The New Zealand government has commissioned research (Youth Transitions, 2003) and implemented strategies (e.g. Taylor, 2004) to try and identify the causes and bring about the solutions to this problem. Understandably much of this is at a macro-level, focussed on communities, organisations and programmes. But for the individual school leavers in transition, the issue is of course, a personal one.

For each, the transition from school is a sort of milestone, marking a degree of independence and decision making which set in train the events that will enable or proscribe options in adult life. The playing field for making decisions is far from level. Many factors intervene to afford some young people more options, and ability to exercise those options, than others. The New Zealand government has recognised this but the degree to which young people recognise and strategize around the issue is less clear.

We know relatively little about the nature and wellsprings of the employment aspirations of New Zealand's schoolleavers despite a 'vast' literature on youth transitions (Morrison \& Loeber, 2004). An international literature has explored relationships between employment destinations and the demographic and geographical background of youth but there are diverse findings and incomplete explanations. Commonly cited among the many factors at play are parental occupation, family socio-economic status and dynamics, schooling, community and labour market characteristics and attachment to the local community. However, Morrison, from a New Zealand perspective, has recently argued that this literature raises as many questions as it answers. How these 'variables' manifest themselves in and through the subjectivity of individuals is just one of the questions. Morrison is not alone in suggesting that at least part of the answer lies in 'aspirations'. However, this perhaps renames rather than resolves the problem: his research shows the paradox of aspiration at odds with reality.

This paper examines the paradox.

\section{Recent New Zealand Research}

Morrison is at the forefront of exploring the issue of employment aspirations among New Zealand secondary school pupils. In work emerging from a collaborative research programme studying attachment in families and communities affected by transience and residential movement Buildiing Attachment in Families and Communities affected by transcience and residential movement, funded by the Foundation for Research, Science and Technology through CRESA, Wellington, he and Loeber surveyed the aspirations of secondary pupils in a decile one metropolitan school and a decile two provincial school. They found, 'contrary to expectations', that aspirations were higher among 'students in a relatively isolated Mill town ...than .... in a metropolitan labour market' (p. 46 - 47). This finding was a 'paradox', in that it was against his assumption that 'schooling in local labour markets of a very different size and character would ....influence students chances of securing a job and modify their educational and occupational aspirations' (p. 46). Moreover, it 'did not support generalisations in the literature about rural and small town youth' (ibid.). Morrison suggests that the links between place and aspiration are more complex than hitherto estimated.

He rightly points to the importance of one stream of education research in the literature examining the impacts of locality and labour markets on youth transitions. Other streams of education research might also be equally useful, in examining the link between locality and aspiration. Moreover, there are New Zealand exemplars. Nash (Nash, 1999; Nash, 2000) applied a model of social capital deriving from Bourdieu to data from his longitudinal study, to illuminate how the aspirations of school students are intimately tied to personal contexts. 
While geographical place was not his prime contextual focus, the notion of social capital is being used widely to illuminate issues of geography and employment, particularly in migration studies (Briggs, 1998; Johnston, 2003; Meyer, 2001; Petit \& McLanahan, 2003; Shah \& Menon, 1999). It is used in this paper to explore the links between aspiration and place in a rural New Zealand, rather than a migration context.

\section{Methodology}

\section{Study Design}

This analysis is drawn from an indepth study of small cohorts of young people over the course of a year, in four different communities. Participants are sampled purposefully to exemplify different experiences of residential mobility in those communities. In semistructured interviews, participants are asked their views of community, school/work, and aspirations for the future, supplemented by a short standardised questionnaire on feelings of attachment to their locality (Gendinning et al., 2003). The interviews are taperecorded and transcribed for discursive analysis. Secondly, individuals are asked to map and explain their social networks. This enables a study of the relationship between 'social capital' and individual thought and action. The notion of social capital utilised here is that of Bourdieu. His core notion is of social capital operating at the level of individuals, and comprised in:

The aggregate of actual or potential resources which are linked to pussession of a durable network of more or less institutionalised relationships of mutual acquaintance or recognition.'(Bourdieu, 1985)

In contrast to models of social capital conceptualised and explored at the level of 'communities' or even nation states (Portes, 1998), Bourdieu treats the concept instrumentally. He focusses on the benefits accruing to individuals depending on their participation in groups, or networks, and on the deliberate construction of sociability to create this resource.

When such an individualised social network approach is combined with an analysis of individuals' discourse, a study can be made directly of the reasons and resources for individuals' actions. Thus the design can directly address 'the question why' which Morrison agrees eludes his level of analysis. Moreover, this paper derives from an emerging programme of collaborative research, of which Morrison's is also a part. The programme is giving rise to a corpus of data and analyses focussed on particulars of 'place', and so provides if not a triangulation of studies, a dialectic in which comparisons and contrast can be made with particular cogency. This study therefore speaks to that of Morrison's in a way unusual between macro- and micro-studies.

\section{The Data}

The data for this paper are from the talk of two 18 year old males from a cohort of seven, in one of the communities of study. The patterns of networks and strategising these young men typify those seen in the cohort, although personal details differ. Their talk and its context of social networks suggest radical connection between social capital accessed through social networks, and expectations and strategising about transition from school to future work.

\section{The Participants}

A's family runs a sheep farm; B's family have a dairy farm. A was sent to boarding school after attending primary school locally; B has completed all his schooling locally. The local school is in the decile 8 category, that of the boarding school, decile 7 .

\section{Results}

\section{Feelings about the Locality}

The young men responded to most of the standardised questions about their local community in a similar way: there were too few shops, it was a safe place for children to grow up in and a 'good place for young people like me' to live. They both disagreed that it felt 'far away from everything', that there was 'nothing for young people like me to do', or that they lacked transport to go and do what they wanted. While both agreed 'people here gossip about everything', neither agreed that it was 'hard to be yourself'. On the other hand, neither felt the "future looks good for young people who stay'.

Significantly, the areas in which the two young men differed in their responses can be seen to relate to their feelings about their social networks. A felt there were 'people I can go to for advice' but B did not; A felt 'there are people who really care about me' but B did not. B and A felt differently about future work, but this again turned on personal networks. A's response to the question 'it would be hard to find a job that suits me here' was to annotate his answer as taking over and redeveloping the family farm. B was 'not a farming boy'; had no such family orientation; no anticipation and indeed an antipathy to future work in the locality generally.

\section{Social Capital, Strategies and Options}

These responses were illuminated by the conversational narratives. From these it is evident that to isolate as causal any 'variable' such as family, school, or indeed socio-economic status fails to comprehend the way these phenomena are experienced as and in, social and emotional networks. These networks deliver information, precedents, contacts and material resources that inform 
and constrain the strategies and aspirations of these young men.

B depicts his world as one where all social networks lie outside the area. B claims minimal local networks. His social world is depicted as fixed in networks out of the locality. These comprise two erstwhile school friends who moved to the city some years ago, but with whom B insists his real 'life' is lead. He rejects the interviewer's assumption that contacts with these friends is in the nature of holidaying:

\section{I: So that's holiday visiting is it?}

\section{B: Well yeah, kind of sort of}

\section{I: But more than holiday?}

B: Yeah well what was it we kind of like live with each other for like a week. I mean when you holiday you don't really.

\section{I: no you don't.}

B: We kind of like live with each other. Which is cool.

In rejecting the notion of merely holidaying, and in insisting 'we kind of like live with each other', both the interviewer and B are accepting B's connections with his city-based friends as something 'more than holiday'. Whereas 'holiday' is transitory and in some sense timeout from real life, B's connections are thus asserted as comprising his real life and real involvement. Despite this, his social network can be surmised as sketchy: his key friend links B to new friends, but this is recent and B knows nothing about them. When pressed, his description of mutual activities is minimal: 'play play station, go clubbing, watch TV, physical activities' and 'clubbing' seems more a claim than a reality since some new friends are underage.

B presents his family as relatively unimportant in his talk about them. No family member is named or described in companionable terms. The age gaps in the family leads B to say 'It feels like two families' and neither father nor mother are described as informed or indeed, even interested parties in B's aspirations for a career in the arts. As B describes it, he is getting minimal help planning this. He has been encouraged by other adults in local cultural groups but his parents are at best sceptical:

B: Well, yeah I mean they all say to me they said it was a dumb thing 'Oh [it is] is a great thing to get into but chances are you know'. I mean 'you don't start off at you're best unless you start off when you're like four or five'. I mean 'they're the ones that um you know have a real good head start on it', they're like so 'Oh well if you want to do that do that then I'm pl= oh well'

I: That's your mum and dad.... You've had a conversation with them about it.

D: Oh Yeah. Oh it wasn't really a conversation it was more I was telling them.
This leaves him with an aspiration 'I'm thinking of going to um what it is I was going to try and get into the National Academy of singing and dramatic art'. But he has no workable plans to achieve this. His city-based erstwhile school friend currently attends a secondary school with an academy sector and B ponders on going there but then what it was I was yapping on to someone else and they said oh stuff the academy thing man do the National Academy thing'. Such an option is almost beyond his conceptual reach. In an intriguing exchange, which is the subject of a forthcoming analysis, B reflects on how his very sense of self is determined by 'place'. He describes how, although reassured that 'well you're good enough', he currently lacks the confidence to take the step:

'Its rather interesting though because I mean in town you know I find that I've actually got a lot more confidence than here? I have no idea about that. I dunno why.... I've sat down and though about that quite a bit.'

School is accorded no importance. "I plod along at my own pace and if I don't really do it I wouldn't have done it with a teacher kind of thing'. In planning an application he rejected help since although 'well she offered to help but I mean oh she's you know if you need anything just ask kind of thing and I'm just like oh yeah I've pretty much got it all sorted anyway. His plans extend only to the knowledge that he has to audition, but although the school year has ended, he has done nothing, and had no resources to do anything practical to make this a reality.

B then, has minimal social capital. His family is disengaged and even antagonistic to his career aspirations. He has no local friendship network and no precedents for tertiary training of any kind. The school has not been a rich site of social capital, local cultural groups do not currently engage him and have not provided connections for pursuit, and his city-based network, in as much as it is a reality, has afforded no avenues to make aspiration into a reality.

In contrast A depicts intense local family and friendship networks. His is family life described as emotionally close, and his contacts regular and relished, and all family members are given personal histories, personalities and current preoccupations. Moreover local contacts are further entrenched through a network of local friends - all at boarding schools out of the area. These are the 'five or six I kept in touch with from form 2' whereas others who remained for local schooling, 'pretty if you meet them you talk to them, but the ones I've really kept in touch with there's probably only four or five'. And again in marked contrast to $\mathrm{B}, \mathrm{A}$ 's school life has been a major focus. Not that A reports epiphanies of learning - subjects at most 'went well' and teachers were professionally rather than personally involved: 'I don't think [they] are really worried. I mean they are paid to worry but I don't think they really worry'. Most salient are the friendship networks then laid down, which reach now across the country. These connections, the activities of those who comprise it and the precedents they constitute, give $\mathrm{A}$ a frame of reference in which tertiary education of some form is taken-for-granted. Many of these peers come from 
contexts not unlike those of B, dairy farmers, small farmer/contractor families, but A's social network is one where all are intent on tertiary training for professional or business careers. This orients A's approach to the family farm

I: Do you have a view of the future then? It seems quite sort of specific.

A: No its no that's why I'm doing this 'cos I hope its quite broad and something's going jump up at me when I'm there. But I've done the school bit to lead into this but I but really don't know what to do. ...

Oh maybe the farm I won't want to be stuck in an office sort of a nine to five job sort of .... and commerce degree would actually give me a bit of background in a way more in the business side .... Dad's still got a few sheep ... I'm still looking at other things I could do with it ... like grapes even ... that's what we're not too sure about but probably it's not too bad.

A's family has been strategic in sorting out A's schooling: they decreed boarding school, making an alternative unthinkable to $\mathrm{A}$, and they decided upon a school too far away to allow weekend commuting. But this prescribed removal from family and place has not lessened A's attachment to either. He wants to stay in the area to work if he can, he feels attached to his family, and they are his main advisors and strategists for tertiary education. He maintains regular contact with his siblings. It was a depiction that led the interviewer to conclude:

I: So though you went to boarding school it didn't really interrupt your family life did it?

A: Nuh not really I mean it did obviously I was away but still stayed pretty close I suppose.

A's aspirations are therefore realistic, well tailored to his secondary school training, specific but not prescriptive or such as to preclude options. The family farm is a potential resource, but it is the social capital accessed through the networks of peers, school and family, which are positioning him to optimise its use. Social capital enables and enhances aspiration based on reality.

\section{Discussion}

Many researchers are revealing 'place' as a mental as much as a physical phenomenon, and as much a social as a material structure and as deeply implicated in individuals' sense of identity (Hay, 1998; Jamieson, 2000; Matthews et al., 1998; Sherlock, 2002; Winstanley et al., 2002). But there are limits on the way place can be 'understood'. Individuals think with the tools and resources available, and geography can impose limits on what they can access in the way of such tools as come to hand through social connections, precedents and information of various kinds. Using a model like that of
Bourdieu's notion of social capital offers a way of systematically examining how 'place' operates through specific mechanisms to delimit the strategic thinking of individuals.

The degree to which either young man in this study is aware of such mechanisms at play is debatable. Deliberate decision-making about schooling would indicate a level of strategic analysis and action in one family, at least. Nor can it be established that either young man relayed the full 'truth' of his or circumstance. In asking about future plans, any school leaver will offer an account that is inevitably also a point of view. There may have been advice or information offered but not reported and parental planning is likely to have been behind the scenes. Pupils may not be aware of schools' strategic planning to create networks and capital (Kelly \& Kenway, 2001) Nevertheless, it is evident that for young people of this age, in this sort of locality, family and school were powerful nodes channelling social capital. In such environments where there is little scope for local peer network developments (Higgins, 2003), these are the key mechanisms of social capital conduit. In such a 'place' these mechanisms enhance or constrain social connection, intellectual, informational and even cognitive resources, and employment information. In so doing they also operate to make real or unreal, the link between aspiration and reality.

\section{References}

Bourdieu, P. (1985), The forms of Capital, in Richardson, J. (ed.), Handbook of Theory and Research for the Sociology of Education, New York, Greenwood

Briggs, X. (1998), Brown kids in white suburbs: Housing mobility and the many faces of social capital, Housing Policy Debte, 9, 1, 177 - 221.

Bynner, J. and Parsons (2002), Social exclusion and the transition from school to work: The case of young people not in education, employment, or training (NEET)' Journal of Vocational Behaviour, 60, 2 , $289-309$.

Gendinning, a., Nuttall, M., Hendry, L., Kloep, M. and Wood, S. (2003), Rural communities and well-being: a good place to grow up? Sociogical Review, 51, 1, 129 - 154.

Hay, R. (1998), Sense of place in developmental context, Journal of Environmental Pychology, 18, 1, 5 - 29.

Higgins, J. (2003), Labour Market Programmes for Young People. A Review. Youth Transitions Report Series 2003, Wellington, Ministry for Social Development.

Jamieson, L. (2000), Migration, place and class: youth in a rural area, The Sociological Review, 48, 2, 203 223. 
Johnston, M. (2003), Bridging social capital in personal networks: an exploratory analysis of data from urban China, Issues and Studies, 39, 3, 177 - 195.

Kelly, P. and Kenway, J. (2001), Managing Youth transitions in the network society, British Journal of Sociology of Education, 22, 19 - 33.

Matthews, H., Limb, M. and Percy-Smith, B. (1998), Changing Worlds: the microgeographies of young teenagers, Tijdschrift voor Economische en Sociale Geografie, 89, 2, 193 - 202.

Meyer, J. (2001), Network approach verses brain drain : lessons from the diaspora, International Migration, 39, 5, 91 - 110.

Morrison, P. and Loeber, E. (2004), Youth Transitions and Place: expectations and the local labour market, Intergenerational Issues, the welfare state and the labour market, Brisbane, Australia.

Nash, R. (1999), Social capital, class identity, and progress at school: Case Studies, New Zealand Journal of Educational Studies, 34, 2, 267 - 280.

Nash, R. (2000), Educational Inequality: the special case of Pacific students, Social Policy Journal of New Zealand, 15, 69 - 86 .

Petit, B. and McLanahan, S. (2003), Residential mobility and children's social capital: Evidence from an experiment, Social Science Quarterly, 84, $3,632-649$
Portes, A. (1998), Social Capital: Its origins and applications in modern sociology, Annual Review of Sociology, 24, 1 - 24.

Shah, N. and Menon, I. (1999), Chain migration through the social network: Experience of labour migrants in Kuwait, International Migration, 37, 2, 361382.

Sherlock, K. (2002), Community matters: Reflections from the field, Sociological Research Online, 7, 2.

Sustainable Development for New Zealand, (2003), Wellington, Department of Prime Minister and Cabinet.

Taylor, L. (2004), Building Social Capital Through Devolved Decision making: the stronger communities Action Fund. Social Policy Journal of New Zealand, 21.

Youth Transitions Report. Executive Summary. Key findings on youth transitions, (2003), Wellington, Ministry of Social Development.

Winstanley, A., Thorns, D. and Perkins, H. (2002), Moving House, Creating Home:Exploring Residential Mobility, Housing Studies, 17, 6, 813 832 . 